\title{
Development of a New Device Implementing Standardized Closed Fracture in the Rat
}

\author{
Nimrod Rozen ${ }^{1,2,3}$, Guy Rubin ${ }^{1, *}$, Lerner Alexande ${ }^{2}$, Lewins on Dina ${ }^{2}$ \\ ${ }^{1}$ Orthopaedic Department, Haemek Medical Center, Afula, Israel \\ ${ }^{2}$ Institute for Research of Bone Repair, Rambam Medical Center, Haifa, Israel \\ ${ }^{3}$ Faculty of Medicine, Technion, Haifa, Israel
}

\begin{abstract}
The objective of the study was to produce a user-friendly device for creating standardized close fracture in an experimental animal. We describe a device that takes advantage of the elastic and plastic nature of the bone for producing a closed fracture with reproducible location and structure. Fractures were produced by a pendulum-like device applying an external blow directly over the tibiae of female Wistar rats fixed to a platform by dynamic holders. The tibiae were immed iately stabilized by plaster fixation that was covered by dental wax. Radiographically, this method resulted in a highly reproducible bi-cortical transverse fracture. Minimal soft tissue damage was noticed around the fracture site. Creatine phosphokinase activity in the serum and in the gastrocnemius muscle of the posterior calf compartment was analy zed in order to evaluate the standardization of the soft tissue damage. The device is simple to build and can be modulated and adapted to different sizes of animals. By using this device, a highly reproducible closed fracture system can be implemented with minimal damage to local soft tissues, but still with the local hematoma that is essential for the fracture healing process.
\end{abstract}

Keywords Fracture Device, Fracture Healing, Bone, Creatine-Phosphokinase, Rat

\section{Introduction}

Creating an animal model is crucial for understanding the cascade of events occurring following a fracture in a long bone. Several approaches to creating closed fractures that imitate a similar fracture in the human long bone have been introduced in the last 20 years.(1-11) In those methods, the bone to be fractured is rigidly fixed to the instrument and is injured by a pendulum, gravity mass, or a piston effect, creating an extramedullary force applied to the desired location that produces a three-point bending effect. The limitation of those approaches are that they do not truly reproduce the bio mechanical sequence of events taking p lace when a human long bone is fractured, because the rigid grasp of the bone limits the elastic and plastic characteristics of the bone

In an attempt to better imitate the biomechanical strain produced at the time of a long bone fracture, we have developed a device that creates a closed transverse fracture in a long bone of the rat in which the bone is being held by dynamic holders situated on a rotating platform. These holders allow the bone to bend under the external force applied until the force overcomes the plastic quality of the

* Corresponding author:

rozen_ni@clalit.org.il (Nimrod Rozen)

Published online at http://journal.sapub.org/ajbe

Copyright (C) 2012 Scientific \& Academic Publishing. All Rights Reserved bone, resulting in a fracture. Moreover, the magnitude of the force of the blow can be adjusted and controlled. The innovation in our method is in exploiting the elastic and plastic properties of the long bone in the environment of a closed fracture.

\section{Materials and Methods}

The device is composed of five basic components (Fig. 1): (a) a platform that supports the animal while the fracture is being produced; (b) a frame supporting a moveable pendulum and an adjustable stopper that limits the depth of the blow to the bone; (c) a pendulum consisting of a steel pole along which a moveable weight glides and that is used to apply the external blow. By changing the position of the weight, one can change the mass of the blow; (d) two specially designed dynamic clamps, each located on a rotating platform that can be adjusted to the size of the limb; and (e) a protractor that enables fixing the pendulum at the angle desired. All co mponents are made of stainless steel.

Sixteen female Wistar rats were randomly divided into two groups: 10 animals served as the experimental group and six as the control group. Animals were anesthetized by intraperitoneal injection of sodium phenobarbital (4mg/100gr body weight, Rhöne Merieux Limited, Harlow, Essex, UK).(12) The left leg of each of the experimental rats was fixed to the device using the dynamic clamps that held both ends of the animal limb. An external blow using an 
equal swing angle of the pendulum was applied to the tibiae. In both groups, the left limbs were immediately fixated in a cast covered by dental wax in order to prevent cast nibbling and breakage by the animals. Animals were free to move in their cage with full weight bearing throughout the entire experimental period, and both groups received the same diet. Radiological and clinical macroscopic assessments were performed. Animals were killed 48 hours post-fracture by a high dose of intraperitoneal nembutal. The experimental protocol was approved by the Animal Care and Use Committee of the Technion Faculty of Medicine

The gastrocnemius muscle was removed from the left leg of all animals, and creatine phosphokinase (CPK) activity was measured in the muscle and in the serum harvested at the time of sacrifice.(13) Fracture sites we re dis sected and their anatomic structure was explored.

Statistical analysis was performed by unpaired $t$-test. Significance level was set at $p<0.05$.

\section{Results}

The device and its detailed elements are demonstrated in figure 1 .

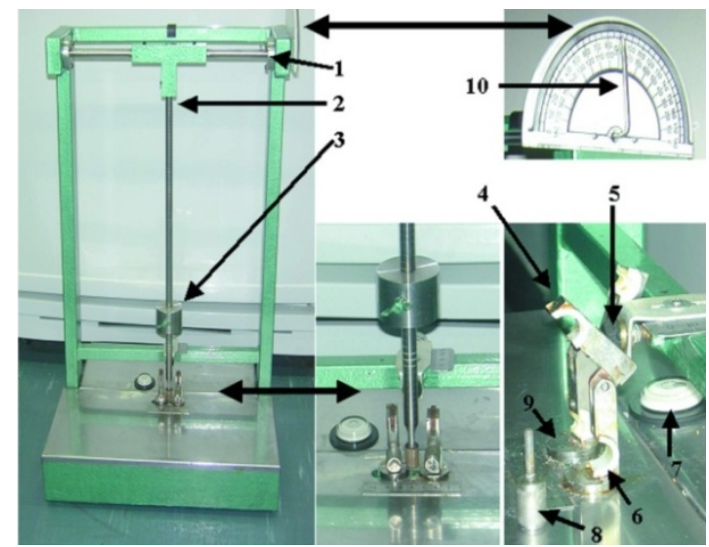

Figure 1. "Rozen fracture device": (1) low-friction cylindrical pole; (2) pendulum; (3) transportable weight; (4) clamp; (5) adjustable stopper that enablesto determine the depth of the blow across thetibial shaft; (6) custom made (adjustable to bone size) tibia holder; (7) spirit level; (8) locking bolt; (9) rotat ing plat form; (10) a protractor that enables to obtain a reproducible blow angle

In all animals, a closed fracture of the tib ia was produced. As demonstrated by radiography and proved by anatomical dissection, all fractures were transverse and uniform (Fig. 2). Minimal soft tis sue damage was noticed around the fracture site, but no open wounds were observed. CPK activity, as anticipated, was significantly higher in the serum of the experimental animals than in the serum of the control rats that were not subjected to a fracture (Fig. 3). The values of CPK activity in the sera of experimental and control rats are given in Tables 1 and 2. As can be seen, the standard deviation in each group was relatively small. On the other hand, CPK level in the gastrocnemius muscle was reciprocally lower $(p<0.0001)$ in the experimental rats than that in the controls, as a result of the lesion caused by the blow. The results are presented in Fig. 4 and Tables 3 and 4 .

Table 1. CPK activity in the serum of experimental rats $(n=6)$

\begin{tabular}{ccc}
\hline $\begin{array}{c}\text { CPK activity } \\
(\mu \mathrm{M} / \mathrm{ml} / \mathrm{min})\end{array}$ & $\begin{array}{c}\text { Soluble protein } \\
\text { content }(\mathrm{mg} / \mathrm{ml})\end{array}$ & $\begin{array}{c}\text { CPK activity } \\
\text { per mg protein }\end{array}$ \\
\hline 73.80 & 15.64 & 4.72 \\
84.30 & 17.01 & 4.96 \\
72.00 & 16.52 & 4.36 \\
68.50 & 15.12 & 4.53 \\
63.02 & 14.98 & 4.21 \\
77.40 & 14.46 & 5.35 \\
\hline
\end{tabular}

Table 2. CPK activity in the serum of control rats $(n=5)$

\begin{tabular}{ccc}
\hline $\begin{array}{c}\mathrm{CPK} \text { activity } \\
(\mu \mathrm{M} / \mathrm{ml} / \mathrm{min})\end{array}$ & $\begin{array}{c}\text { Soluble protein } \\
\text { content }(\mathrm{mg} / \mathrm{ml})\end{array}$ & $\begin{array}{c}\text { CPK activity per } \\
\text { mg protein }\end{array}$ \\
\hline 53.30 & 17.25 & 3.09 \\
43.50 & 16.03 & 2.71 \\
41.18 & 14.4 & 2.86 \\
38.80 & 15.89 & 2.44 \\
35.70 & 15.67 & 2.28 \\
\hline
\end{tabular}

Table 3. CPK act ivity in the gastrocnemius muscle of experimental rats ( $n$ =9)

\begin{tabular}{ccc}
\hline $\begin{array}{c}\text { CPK activity } \\
(\mu \mathrm{M} / \mathrm{ml} / \mathrm{min})\end{array}$ & $\begin{array}{c}\text { Soluble protein } \\
\text { content }(\mathrm{mg} / \mathrm{ml})\end{array}$ & $\begin{array}{c}\text { CPK act ivity per } \\
\text { mg protein }\end{array}$ \\
\hline 39.86 & 6.97 & 5.72 \\
38.48 & 7.49 & 5.14 \\
26.82 & 7.57 & 3.54 \\
37.20 & 11.80 & 3.15 \\
27.96 & 9.54 & 2.93 \\
60.71 & 8.81 & 6.89 \\
74.70 & 10.18 & 7.34 \\
65.50 & 14.21 & 4.61 \\
53.90 & 12.03 & 4.48 \\
\hline
\end{tabular}

Table 4. CPK activity in the gastrocnemius muscle of control rats $(n=6)$

\begin{tabular}{ccc}
\hline $\begin{array}{c}\text { CPK activity } \\
(\mu \mathrm{M} / \mathrm{ml} / \mathrm{min})\end{array}$ & $\begin{array}{c}\text { Soluble protein } \\
\text { content }(\mathrm{mg} / \mathrm{ml})\end{array}$ & $\begin{array}{c}\text { CPK activity per } \\
\text { mg protein }\end{array}$ \\
\hline 55.88 & 9.52 & 5.87 \\
71.75 & 10.22 & 7.02 \\
68.30 & 10.01 & 6.82 \\
76.40 & 10.46 & 7.30 \\
78.3 & 11.02 & 7.11 \\
83.7 & 13.41 & 6.24 \\
\hline
\end{tabular}

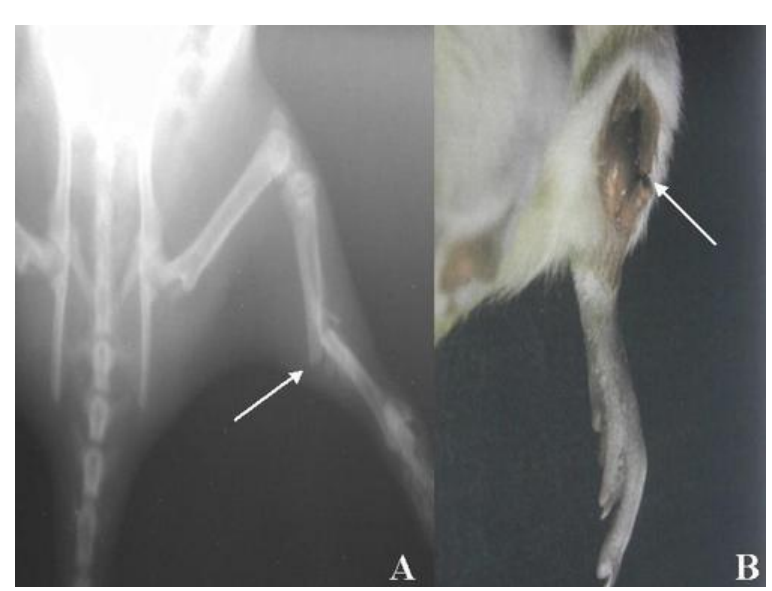

Figure 2. A- Radiograph demonstrating a typical transverse fracture (arrow) in the rat tibia that was obtained by the "Rozen fracture device", BDissection of the fracture area (arrow) 


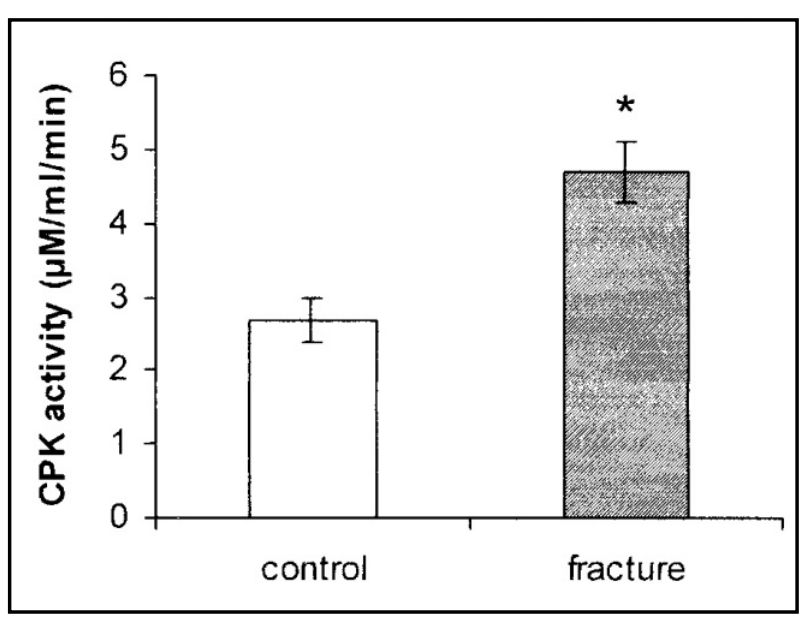

Figure 3. CPK activity in mg protein of serum of rats after fract ure shows a significant increase in the sera of fractured rats as compared with control rats. ${ }^{*} p<0.0001$

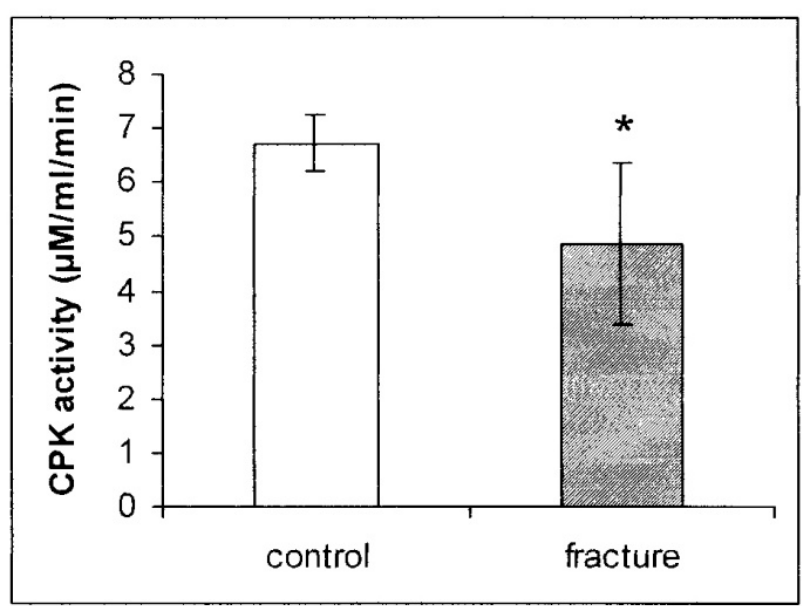

Figure 4. CPK activity in mg protein of the gastrocnemius muscle of rats after fracture shows a reciprocal decrease in the muscles of fractured rats as compared with control rats. $p=0.0162$

\section{Discussion}

The production of a standard closed fracture was accomplished using a simple and rather inexpensive device that can be built in any laboratory. The device enables calculation of both the mo mentum and the total force applied on the limb, simply by knowing the weight at the distal pole of the pendulum and the angle to which it was elevated previous to the swing. As in human patients, the structure of the fracture and the extent of the soft tissue damage are related to the loading forces applied by the device.

Most of the methods producing fractures that have been described in the literature until now make use of an open procedure, either by cutting the skin and muscles over the site of the bone to be fractured by cutting,(14) or by creating a closed fracture with devices that do not take in consideration the elastic and plastic properties of the bone. $(1,3,4)$ In the device presented here, the rotating platform clamps mimic the adjacent joints' movement that takes place at the time of fracture and enable the long bone to explore its mechanical properties. Moreover, internal fixation of the fracture through nailing $(11,15,16)$ has the following disadvantages: a) it necessitates an additional cut; b) reduces the mechanical properties of a long bone, which necessitates an additional cut; c) creates a drainage pathway for the hemato ma initiated by the fracture. The hemato ma is a necessary preliminary step in the cascade of events during the process of fracture healing.

CPK enzyme activity in the serum of the treated animals showed a uniform and statistically significant increase of about $175 \%$ when compared with CPK enzyme activity in the control rats, as well as a decrease of $28 \%$ in the calf muscles. These results demonstrate that using the device of implementing a fracture as described in this paper produces a reproducible fracture pattern, as well as equal and minimal damage to the surrounding soft tissue around the fracture. Moreover, we suggest that the fracture caused by this device and the following healing process present a reliable reproduction of the physiological healing process of closed fractures in the human patient.

In conclusion, our device is simple to build and might be modulated and adapted to different sizes of animals. By using this device, a highly reproducible closed fracture system can be introduced with minimal damage to local soft tissues, but still with the local hematoma that is essential for the fracture healing process.

\section{ACKNOWLEDGEMENTS}

The authors express their appreciation for the contribution of Mr. Yigal Zuker, the Intitute's Head Instrumentation Technician, to the building of the fracture device.

\section{REFERENCE}

[1] Bonnarens F, Einhorn TA. Production of a standard closed fracture in laboratory animal bone. $\mathrm{J}$ Orthop Res 1984;2(1):97-101.

[2] Knowles JC, Sell PJ, Templeton J, Hastings GW. A simple device for the production of an experimental fracture in the rat femur. J Biomed Eng 1991;13(2):176.

[3] Macdonald W, Skirving AP, Scull ER. A device for producing experimental fractures. Acta Orthop Scand 1988;59(5):542-544.

[4] Park SH, Cassim A, Llinas A, McKellop HA, Sarmiento A. Technique for producing controlled closed fractures in a rabbit model. J Orthop Res 1994;12(5):732-736.

[5] Tatari H, Fidan M, Erbil G, Koy uncuoglu M, Karci T, Destan $\mathrm{H}$, Tekmen I. A new device to produce a standardized experimental fracture in the rat tibia. Saudi Med J 2007;28(6.871-866:(

[6] Ashhurst DE, Hogg J, Perren SM. A method for making reproducible experimental fractures of the rabbit tibia. Injury 1982;14(3):236-242. 
[7] Cheal EJ, Mansmann KA, DiGioia AM, III, Hayes WC, Perren SM. Role of interfragmentary strain in fracture healing: ovine model of a healing osteotomy. J Orthop Res 1991;9(1):131-142.

[8] Davy DT, Connolly JF. The biomechanical behavior of healing canine radii and ribs. J Biomech 1982;15(4):235-247.

[9] Hiltunen A, Vuorio E, Aro HT. A standardized experimental fracture in the mouse tibia. J Orthop Res 1993;11(2):305-312

[10] Toombs JP, Wallace LJ, Bjorling DE, Rowland GN. Evaluation of Key's hypothesis in the feline tibia: an experimental model for augmented bone healing studies. Am J Vet Res 198.518-513:(2)46;5

[11] Manigrasso MB, O'Connor JP. Characterization of a closed femur fracture model in mice. $\mathrm{J}$ Orthop Trauma 2004;18(10):687-695.

[12] Auer JA, Goodship A, Arnoczky S, Pearce S, Price J, Claes L, von RB, Hofmann-Amtenbrinck $\mathrm{M}$, Schneider $\mathrm{E}$,
Muller-Terpitz R, Thiele F, Rippe KP, Grainger DW. Refining animal models in fracture research: seeking consensus in optimising both animal welfare and scientific validity for appropriate biomedical use. BMC Musculoskelet Disord 2007;8:72.

[13] TANZER ML, GILVARG C. Creatine and creatine kinase measurement. J Biol Chem 1959;234:3201-3204.

[14] Molster AO, Gjerdet NR, Alho A, Bang G. Fracture healing after rigid intramedullary nailing in rats. Acta Orthop Scand 1983;54(3):366-373

[15] Holstein JH, Menger MD, Culemann U, Meier C, Pohlemann T. Development of a locking femur nail for mice. J Biomech 2007;40(1):215-219.

[16] Holstein JH, Matthys R, Histing T, Becker SC, Fiedler M, Garcia P, Meier C, Pohlemann T, Menger MD. Development of a stable closed femoral fracture model in mice. J Surg Res 2009;153(1):71-75. 